\title{
Effect of benazepril on the transdifferentiation of renal tubular epithelial cells from diabetic rats
}

\author{
TAO PENG $^{1}$, JIE WANG ${ }^{1}$, JUNHUI ZHEN ${ }^{2}$, ZHAO HU $^{1}$ and XIANGDONG YANG ${ }^{1}$ \\ Departments of ${ }^{1}$ Nephrology and ${ }^{2}$ Pathology, Shandong University, \\ Qilu Hospital, Jinan, Shandong 250012, P.R. China
}

Received December 30, 2013; Accepted March 11, 2014

DOI: $10.3892 /$ br.2014.277

\begin{abstract}
The aim of this study was to investigate the effect of benazepril on the transdifferentiation of renal tubular epithelial cells from diabetic rats. Thirty male Sprague-Dawley rats were included in the present study. Eight of the 30 rats were randomly selected and served as the normal control group ( $\mathrm{N}$ group), while the remaining 22 rats, injected with streptozotocin (STZ), comprised the diabetic rat model. Rats with diabetes were randomly divided into the diabetic (DM group) and benazepril (B group) groups. The total course was conducted over 12 weeks. Blood glucose, body weight, kidney/body weight, 24-h urinary protein, serum creatinine and blood urea nitrogen were measured at the start and end of the study. We observed the tubulointerstitial pathological changes, and applied immunohistochemistry and western blotting to detect the expression of $\alpha$-smooth muscle actin ( $\alpha$-SMA) in renal tissue. The levels of blood glucose, kidney/body weight, 24-h urinary protein, serum creatinine, blood urea nitrogen and tubulointerstitial damage index (TII) in the DM group were significantly higher than that in the $\mathrm{N}$ group $(\mathrm{p}<0.01)$. Except for blood glucose and kidney/body weight, the remaining indices were lower in the B group compared with those in the DM group $(\mathrm{p}<0.01)$. Immunohistochemical staining results revealed the expression of $\alpha$-SMA in renal tubular epithelial cells to be significantly higher in the DM and B groups compared with the control (N) group $(\mathrm{p}<0.01)$. Western blot analysis revealed that the expression of $\alpha$-SMA in diabetic renal tissue increased 3.27-fold compared with that of the $\mathrm{N}$ group, while the expression of $\alpha$-SMA in the B group decreased $45 \%$ compared with that in the DM group. In conclusion, benazepril significantly reduced the expression of $\alpha$-SMA in renal tubular epithelial cells obtained from diabetic rats, inhibited the transdifferentiation
\end{abstract}

Correspondence to: Dr Tao Peng and Dr Zhao Hu, Department of Nephrology, Shandong University, Qilu Hospital, No. 107 Wenhua Xi Road, Jinan, Shandong 250012, P.R. China

E-mail: lichee@126.com

E-mail: qiluhospital@126.com

Key words: diabetic nephropathy, benazepril, renal tubular epithelial cells, $\alpha$-smooth muscle actin, angiotensin II of renal tubular epithelial cells and played an important role in kidney protection.

\section{Introduction}

Diabetic nephropathy (DN) is a progressive kidney disease and a major debilitating complication of type 1 and type 2 diabetes that can lead to chronic kidney disease (CKD) and related cardiovascular disorders. Proteinuria is an early clinical manifestation of diabetic nephropathy, resulting in rapid progression of renal disease with initial development of pathological features of glomerulosclerosis and tubulointerstitial fibrosis (1). Thus, it is crucial to develop methods to arrest or retard glomerulosclerosis and tubulointerstitial fibrosis.

Epithelial-mesenchymal transition (EMT) plays a pivotal role in organ fibrosis, including that of kidney $(2,3)$. It has been reported that a large proportion of the interstitial fibroblasts in fibrotic kidneys originate from proximal tubular cells (4). EMT involves a series of changes through which epithelial cells lose their epithelial characteristics and acquire properties typical of mesenchymal cells. EMT facilitates cell movement and the generation of new tissue types during development and contributes to the pathogenesis of disease. Transduction of EMT of tubular cells into $\alpha$-smooth muscle actin ( $\alpha$-SMA)-expressing myofibroblasts is a central mechanism in tubulointerstitial fibrosis. The expression of $\alpha$-SMA occurs only in the vascular smooth muscle cells of the normal kidney. The presence of $\alpha$-SMA in mesangial, renal tubular epithelial and other inherent cells, would indicate that EMT has occurred in the site of the lesion. Synthesis and secretion of ECM with myfibroblastic characteristics are initiated via inherent cells (4).

Angiotension-converting enzyme inhibitors (ACEIs) are used to retard the progression of fibrosis in diabetic nephropathy and renal failure. Data from the Angiotensin-ConvertingEnzyme Inhibition in Progressive Renal Insufficiency (AIPRI) trial and The Raminipril Efficacy In Nephropathy (REIN) study showed that ACEIs are capable of significantly retarding the rate of decline in renal function $(5,6)$. A review based on a series of studies including the REIN study, concluded that urinary protein is one of the main mediators of glomerular damage to the tubulointerstitium, and that ACEIs can confer renoprotection via a reduction in urinary protein excretion in progressive kidney diseases (7). ACEIs have also been shown 
to slow the progression of nephropathy in type 1 diabetes patients, although the effects of ACE inhibition remain inconclusive, possibly due to its heterogeneous nature (8).

In the present study, we evaluated the efficiency of benazepril, a type of ACEI, mitigating EMT in a streptozocin (STZ)-induced $\mathrm{DM} / \mathrm{N}$ rat model, and clarified the exact mechanism of benazepril in protecting the kidney.

\section{Materials and methods}

Experimental animals. In total, 30 healthy adult male Sprague-Dawley rats (SD rats, clean grade), weighing 190-200 g were included in the present study. The rats were purchased from the Beijing Vital River Laboratory Animal Technology Company and reared in the Qilu Hospital of Shandong University Experimental Animal Center. The animals were provided the standard diet and water ad libitum, and were housed at a temperature of $21 \pm 1^{\circ} \mathrm{C}$, with $60-70 \%$ relative humidity and 12-h light/dark cycle.

Drugs and reagents. Benazepril hydrochloride (Lotensin, Beijing Novartis, Pharma Ltd., Beijing, China) was equipped with distilled water to a appropriate concentration prior to application. STZ (Sigma, St. Louis, MO, USA), mouse antirat $\alpha$-smooth muscle actin ( $\alpha$-SMA) monoclonal antibody (Abcam, Cambridge, UK), biotin-labeled goat anti-mouse $\mathrm{IgG}$, goat anti-mouse secondary antibody kit (Zhongshan Golden Bridge Biotechnology Co., Ltd., Beijing, China) and ECL luminescent liquid and PVDF membrane (Millipore Corporation, Billerica, MA, USA) were prepared.

Establishment of STZ-induced DN rat model. All 30 rats were fed for one week and the experiment began after $12 \mathrm{~h}$ of fasting. Eight rats were randomly selected as the control group (N group), and the remaining 22 rats were injected with STZ with $60 \mathrm{mg} / \mathrm{kg}$ once in the lower left abdominal region. Prior to use, STZ was prepared as $1 \%$ concentration with citratesodium citrate buffer solution $(0.1 \mathrm{~mol} / 1, \mathrm{pH} 4.2)$. The rats in the $\mathrm{N}$ group were injected with an equivalent citrate-sodium citrate buffer. After $72 \mathrm{~h}$, three consecutive random blood glucose $(\mathrm{BG})$ samples were obtained from tail vein of rats and measured. When BG was $>16.7 \mathrm{mmol} / 1$, the diabetes model was considered successful (9).

Randomization and treatment. Twenty-two rats from the successful diabetes model were randomly divided into the diabetic (DM group, $n=11$ ) and benazepril (B group, $n=11$ ) groups. After four weeks, the rats were gavaged once daily. Rats in the B group received $10 \mathrm{mg} / \mathrm{kg} /$ day benazepril, and rats in the $\mathrm{N}$ and DM groups were treated with the same amount of distilled water. All 22 rats were gavaged for 8 weeks. The animals were provided the standard diet and water ad libitum without insulin and antidiabetic drugs throughout the experimental period.

Specimen collection. Random BG obtaine from the tail vein of rats and body weight (BW) were measured weekly. The rats were placed in metabolic cages in order to collect 24-h urine volume one day prior to sacrifice. The urine specimens were centrifuged and placed in a freezer at $-20^{\circ} \mathrm{C}$ and the urine protein was measured. Prior to sacrifice, the animals were anesthetized with $4 \mathrm{ml} / \mathrm{kg} 10 \%$ chloral hydrate by intraperitoneal injection (10). Subsequently, blood was collected from the inferior vena cava and centrifuged at $4^{\circ} \mathrm{C}$ to obtain serum which was stored at $-80^{\circ} \mathrm{C}$ for the measurement of $\mathrm{BG}$, serum creatinine (SCr), and blood urea nitrogen (BUN). The left ventricle was injected with pre-chilled $4^{\circ} \mathrm{C}$ saline, the right atrium was cleaved and drained, and the kidneys were repeatedly lavaged until the entire kidney was pale in color prior to stripping and removing of the capsule. Saline $(0.9 \%)$ was applied to the kidney without via syringe. The kidney was dried with filter paper and weighed. Subsequently, it was cut along the coronal plane, placed in $10 \%$ neutral formalin solution, fixed, and maintained for histopathological and immunohistochemical examination.

The remaining kidney tissue was placed in liquid nitrogen, frozen at $-80^{\circ} \mathrm{C}$ in a freezer and subsequently used for the western blot analysis.

Pathology assessment. Thirty non-overlapping tubulointerstitial visions (no glomerular and vascular) with PAS staining at high magnification (x400) were randomly selected to determine the tubulointerstitial damage index (TII) (11), namely known as a percentage of the tubulointerstitial damage area to the total same vision area. Scoring was performed as follows: 0, normal; 1 point: $<25 \%$; 2 points: $25-50 \%$; 3 min: $>50 \%$.

Immunohistochemical measurement. The expression of $\alpha$-SMA was measured using an SABC assay (12). Pathological slices of renal tissue were dewaxed, heated in a microwave at $92-95^{\circ} \mathrm{C}$ for $15 \mathrm{~min}$, and fixed with $0.1 \mathrm{M}$ citrate buffer ( $\mathrm{pH}$ 6.0). Then, 3\% hydrogen peroxide was used to develop biotin and peroxidase inactivation. Renal tissue was then added to goat serum blocking solution, incubated for $30 \mathrm{~min}$ at $37^{\circ} \mathrm{C}$, and mouse anti-rat $\alpha$-SMA (1:50) monoclonal antibody was added prior to incubation at $4^{\circ} \mathrm{C}$ overnight. The following day, biotinylated secondary antibody and streptavidin working solution were added dropwise, and DAB staining was visualized using a Nikon epifluorescence E600 microscope. Renal tissue slices were restained with hematoxylin, dehydrated and differentiated using hydrochloric acid alcohol, mounted with neutral gum. PBS was used as a negative control instead of the primary antibody. Staining was considered positive when granules were brown. Immunohistochemical image analysis was performed as follows: tubulointerstitial-positive regional optical density $[\mathrm{D}(\lambda)]$ was calculated by image analysis software (Leica Imaging systems Ltd., Cambridge, UK) in each slice and the mean value was adopted (13).

Western blot analysis. RIPA lysate $(1 \mathrm{ml})$ was added to kidney tissue $(100 \mathrm{mg})$ and homogenized. The homogenates were centrifuged at $4^{\circ} \mathrm{C}$ for $9,180 \mathrm{x} \mathrm{g}$ for $5 \mathrm{~min}$, and the supernatant was collected to measure the protein concentration. Then, $50 \mathrm{mg}$ sample was added to the sample buffer and boiled for 5 min. After SDS-PAGE (12\% electrophoresis gel, 6\% stacking gel), the sample was transferred to a PVDF membrane and incubated for $1.5 \mathrm{~h}$ in $5 \%$ skimmed milk at room temperature. Mouse anti-rat $\alpha$-SMA (1:250) monoclonal antibody was then added at $4^{\circ} \mathrm{C}$ after washing the membrane. The following day, the sample was incubated with HRP-conjugated secondary 
Table I. General index in each group (mean \pm SD).

\begin{tabular}{lccccccc}
\hline Group & $\mathrm{n}$ & $\begin{array}{c}\mathrm{BG} \\
(\mathrm{mmol} / \mathrm{l})\end{array}$ & $\begin{array}{c}\mathrm{BW} \\
(\mathrm{g})\end{array}$ & $\begin{array}{c}\mathrm{KW} / \mathrm{BW} \\
\left(\mathrm{x} 10^{-3}\right)\end{array}$ & $\begin{array}{c}24-\mathrm{h} \text { urine protein } \\
(\mathrm{mg} / 24 \mathrm{~h})\end{array}$ & $\begin{array}{c}\mathrm{SCr} \\
(\mu \mathrm{mol} / \mathrm{l})\end{array}$ & $\begin{array}{c}\mathrm{BUN} \\
(\mathrm{mmol} / \mathrm{l})\end{array}$ \\
\hline $\mathrm{N}$ & 8 & $7.83 \pm 0.45$ & $245.37 \pm 18.55$ & $4.23 \pm 0.18$ & $9.18 \pm 0.81$ & $20.73 \pm 1.87$ & $5.67 \pm 1.52$ \\
$\mathrm{DM}$ & 7 & $26.38 \pm 3.41^{\mathrm{a}}$ & $178.67 \pm 5.03^{\mathrm{a}}$ & $8.78 \pm 0.16^{\mathrm{a}}$ & $7.10 \pm 3.58^{\mathrm{a}}$ & $83.89 \pm 2.09^{\mathrm{a}}$ & $25.23 \pm 3.58^{\mathrm{a}}$ \\
$\mathrm{B}$ & 8 & $25.25 \pm 2.54$ & $176.34 \pm 4.46$ & $6.12 \pm 0.23^{\mathrm{b}}$ & $43.58 \pm 3.68^{\mathrm{b}}$ & $54.89 . \pm 4.14^{\mathrm{b}}$ & $12.36 \pm 2.83^{\mathrm{b}}$ \\
\hline
\end{tabular}

${ }^{\mathrm{a}} \mathrm{P}<0.01$ vs. $\mathrm{N}$ group. ${ }^{\mathrm{b}} \mathrm{P}<0.01$ vs. $\mathrm{DM}$ group. $\mathrm{BG}$, blood glucose; $\mathrm{BW}$, body weight; $\mathrm{SCr}$, serum creatinine; BUN, blood urea nitrogen; $\mathrm{N}$, normal group; DM, diabetic group; B, benazepril group.

antibody $(1: 10,000)$ at room temperature, $1 \mathrm{~h}$, after washing the membrane again. ECL luminescence was performed, and the X-ray film was developed and fixed following modereate exposure. Image J analysis system (National Institute of Mental Health, Bethesda, MD, USA) was used to scan the hybridization signals on optical density. $\beta$-actin was applied as a protein control and the mean value was measured by comparing the other groups to obtain the relative amounts.

Statistical analysis. Samples were assessed using SPSS17.0 statistical software. Measurement data were expressed as mean \pm SD. Groups were compared using ANOVA and pairwise using LSD test. $\mathrm{P}<0.05$ was considered statistically significant.

\section{Results}

General. In the N group, normal state of drinking water, fur color and mental status was maintained. However, in the DM group, the model rats exhibited polydipsia, polyphagia and polyuria. Extension of the course gray fur, weight loss, slow reaction and other symptoms were also observed in rats of the DM group. Seven rats died during the course of the experiment, 4 in the DM group and 3 in the $\mathrm{N}$ group.

General index. The level of BG , kidney weight/body weight, 24-h urine protein, $\mathrm{SCr}$ and BUN were significantly higher in the DM group compared to that in the $\mathrm{N}$ group $(\mathrm{p}<0.01)$. However, body weight was significantly lower in the DM group compared to that in the $\mathrm{N}$ group. In addition to $\mathrm{BG}$ and body weight, the remaining indicators were significantly lower in the B group compared to the DM group $(\mathrm{p}<0.01)$ (Table I).

Pathological changes. In the $\mathrm{N}$ group, there was clear structure without any renal tubulointerstitial disease in kidney tissue with PAS staining by light microscopy. But in the DM group, significant expansion of tubules, tubular epithelial cell granules degeneration, basement membrane thickening, and inflammatory cells infiltration increasing in interstitial were seen in kidney tissue with PAS staining by light microscopy. The above-mentioned lesions in group B were significantly reduced compared with the DM group. Results of the statistical analysis revealed that TII in the DM group was significantly higher than that in the $\mathrm{N}$ and $\mathrm{B}$ groups (all p<0.01) (Fig. 1, Table II).

Expression of $\alpha$-SMA by immunohistochemistry. In group $\mathrm{N}$, the expression of $\alpha$-SMA was only observed on smooth muscle
Table II. Expression of TII and $\alpha$-SMA in renal tubulo-interstitium $[\mathrm{D}(\lambda)$, (mean $\pm \mathrm{SD})]$.

\begin{tabular}{lccc}
\hline Group & No. & TII & $\alpha$-SMA \\
\hline $\mathrm{N}$ & 8 & $0 \pm 0$ & $0.52 \pm 0.27$ \\
$\mathrm{DM}$ & 7 & $2.7 \pm 0.5^{\mathrm{a}}$ & $16.23 \pm 1.67^{\mathrm{a}}$ \\
$\mathrm{B}$ & 8 & $1.5 \pm 0.3^{\mathrm{b}}$ & $8.23 \pm 0.69^{\mathrm{b}}$ \\
\hline
\end{tabular}

${ }^{\mathrm{a}} \mathrm{P}<0.01$ vs. the $\mathrm{N}$ group. ${ }^{\mathrm{b}} \mathrm{P}<0.01$ vs. the $\mathrm{DM}$ group. $\alpha$-SMA, $\alpha$-smooth muscle actin; TII, tubulointerstitial damage index; N, normal group; DM, diabetic group; B, benazepril group.

cells of the vessel wall in renal tubular-interstitium. However, $\alpha$-SMA was mainly expressed in the renal tubular epithelial cells and interstitial tubules in addition to the vessel wall in the DM group, and significantly increased compared with the $\mathrm{N}$ group $(\mathrm{p}<0.01)$. Expression of $\alpha$-SMA was significantly reduced in the B group compared with the DM group $(\mathrm{p}<0.01)$ (Table II and Fig. 2).

Expression of $\alpha$-SMA by western blotting. Analysis of the optical density of bands by western blotting showed that the expression of $\alpha$-SMA in renal tissue increased 3.27-fold in the DM group compared with the $\mathrm{N}$ group, and increased by 1.22 -fold in the DM group compared with the B group (Fig. 3).

\section{Discussion}

In the present study, the STZ-induced diabetic rat model was successfully produced by a single intraperitoneal injection. At the 12th week of experiment, 24-h urine protein and SCr of diabetic model rats showed a marked increase. The main pathological changes of the kidney were glomerular hypertrophy, mesangial matrix increasing, tubular epithelial granule cells and degeneration, tubular dilation and irregular thickening of the basement membrane. Small focal mononuclear-macrophage infiltration was evident in tubulointerstitium. These changes indicated that the STZ-induced diabetic rat model was successful.

Most previous studies have focused on glomerular lesions in diabetic nephropathy (DN), while other studies have focused on tubulointerstitial injury (14). It has been shown that while the glomerular filtration membrane changes in DN, tubulointerstitial lesions have been previously described (15). The 

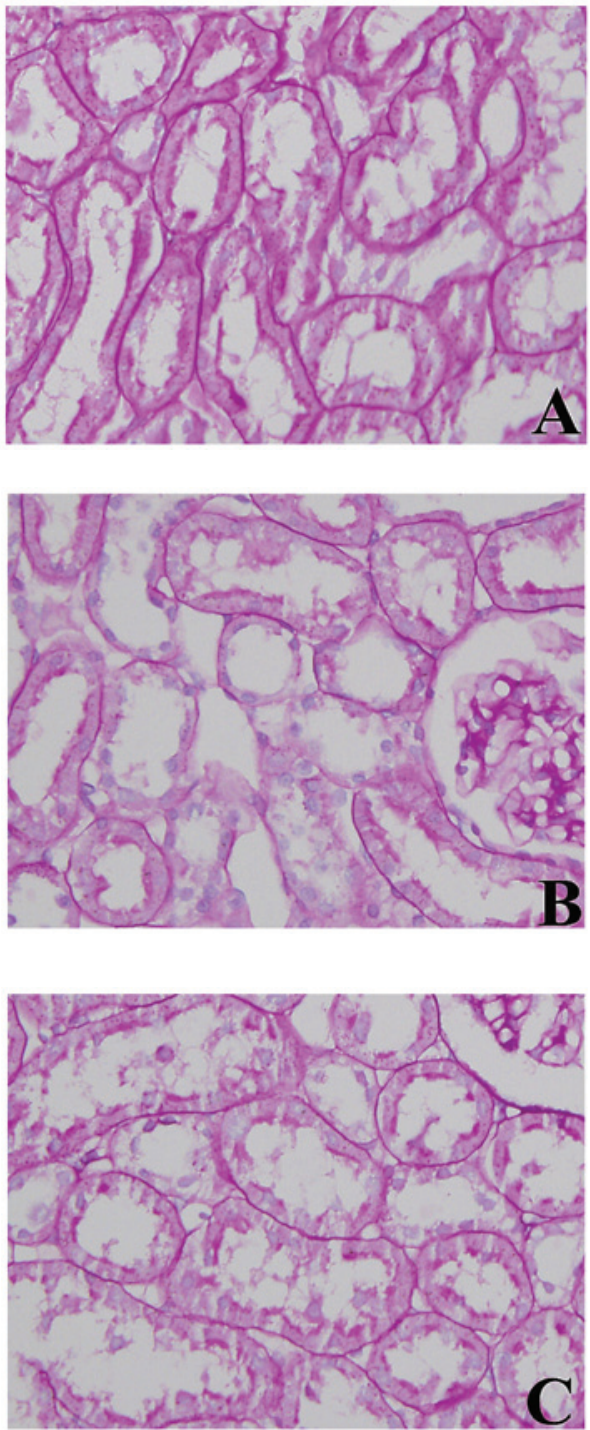

Figure 1. Pathological changes of rat renal tubulointerstitium in each group (PAS staining; magnification, $\mathrm{x} 400)$. (A) Control (N), (B) diabetic (DM) and (C) benazepril (B) groups.

results of this study have shown that tubulointerstitial injury is not entirely dependent on the glomerular lesions and is itself an independent factor of DN. There is a close correlation between the serious extent of tubulointerstitial lesions, degree of urinary protein excretion and renal function deterioration under high glucose conditions, which directly affect the prognosis of DN. Therefore, strengthening the study of renal tubular interstitial lesion of DN is of clinical significance.

Renal interstitial fibrosis (RIF) is the final outcome of DN (16). Studies have shown that EMT is a key link in the process of RIF, and is one of the initial aspects of occurrence and development of RIF (17). Studies confirmed that in the chronic renal interstitial fibrosis model, myofibroblast cells from the transdifferentiation of tubular epithelial cells accounted for $36 \%$ of all myofibroblasts in renal interstitium. Inhibiting or reversing EMT in delaying the progression of DN is of clinical significance (4).

$\alpha$-SMA has been widely used to detect EMT as a marker protein of myofibroblasts (18). There are almost no myofibroblasts in normal kidney tissue, and the expression of $\alpha$-SMA is
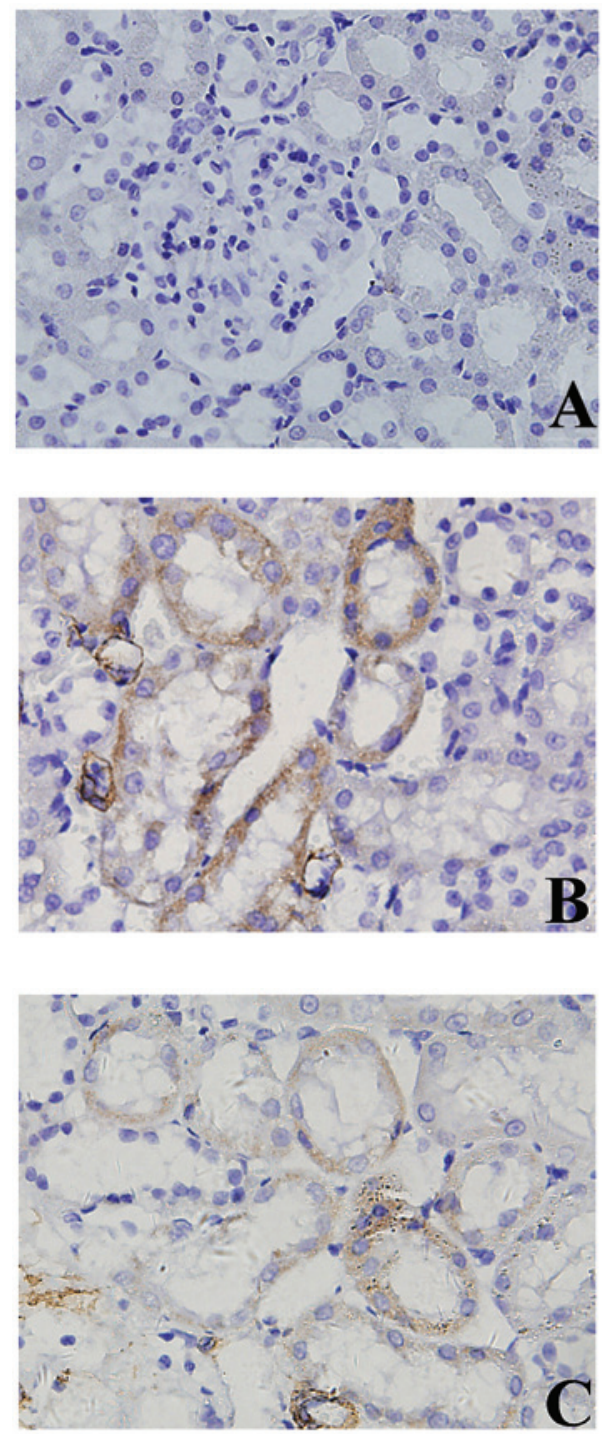

Figure 2. $\alpha$-SMA expression in rat renal tubulointerstitium in each group (SABC assay; magnification, $x 400)$. (A) Control (N), (B) diabetic (DM) and (C) benazepril (B) groups. $\alpha$-SMA, $\alpha$-smooth muscle actin.
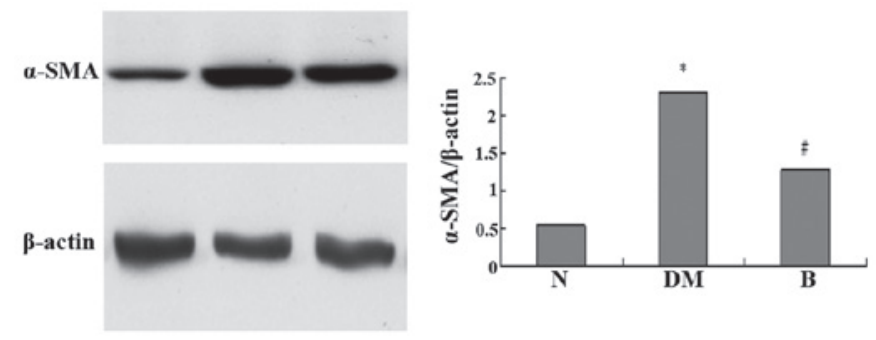

Figure 3. Expression of $\alpha$-SMA in renal tissue by western blotting. " $\mathrm{P}<0.01$ vs. the $\mathrm{N}$ group, ${ }^{\prime \prime} \mathrm{P}<0.01$ vs. the DM group. $\alpha$-SMA, $\alpha$-smooth muscle actin. $\mathrm{N}$, normal group; DM, diabetic group; $\mathrm{B}$, benazepril group.

only evident in the vascular smooth muscle cells of kidney. When $\alpha$-SMA is expressed in glomerular mesangial and renal tubular epithelial cells, EMT has occurred. These intrinsic cells began to synthesize and secrete extracellular matrix (ECM), which possess the characteristics of myofibroblasts (19). In the present study, the expression of $\alpha$-SMA was significantly increased by immunohistochemistry and western blotting in the 12th week, 
mainly in renal tubular epithelial cells, consistent with the tubulointerstitial damage area in tubulointerstitium of DM model rats, with TII being significantly increased as compared to the $\mathrm{N}$ group. These results showed that some tubular epithelial cells already express $\alpha$-SMA and that EMT has occurred in the early stages of DN, with myofibroblast phenotypic characteristics.

Renin-angiotensin system (RAS) and its receptor are active in the diabetic state, and there is an excess of angiotensin II (Ang II) generation in local tissue of kidney. Ang II leads to abnormalities of renal blood flow dynamics in diabetic state and participates in tubulointerstitial fibrosis in a non-hemodynamic manner (20). By RAS and AT1 receptors, Ang II stimulates renal tubular epithelial cell hypertrophy, induces the synthesis of TGF- $\beta 1$, and generates interstitial fibroblasts and tubular epithelial cells into myofibroblasts. Consequently, the generation of ECM increases, degradation decreases and ultimately the result is tubulointerstitial fibrosis. In addition, Ang II, as an inflammatory cytokine, can cause an inflammatory initiation factor, nuclear factor $-\kappa \mathrm{B}(\mathrm{NF}-\kappa \mathrm{B})$, to activate and shift in the early stages of DN, leading to ICAM-1, MCP-1, OPN, other cytokines and an increase in adhesion molecule expression, which recruits a large number of inflammatory cell infiltration to glomerular and tubulointerstitium (21). Expression of TGF- $\beta 1$, CTGF and other factors increased because of the role of inflammation in the kidney, and at the same time fibroblasts proliferate and transdifferentiated into myofibroblasts. Yang et al also confirmed that Ang II significantly increased the ability of TNF- $\beta 1$-induced tubular epithelial cells to transdifferentiate into myofibroblasts (22).

As a typical representative of ACEI drugs, benazepril has been widely used in the treatment of DN due to decreasing blood pressure and proteinuria. The present study showed that at end of the 12th week, kidney weight/body weight, 24-h urinary protein, SCr, BUN and TII were significantly ameliorated in the B group compared with the DM group, and $\alpha$-SMA expression was significantly reduced in the B group compared with the DM group. The results of present study show that benazepril exerted protective effects on DN, which may be associated with the inhibition of excessive $\alpha$-SMA expression and renal tubular EMT in diabetic kidney tissue.

In conclusion, the present study has shown that benazepril ameliorates renal structural and functional damage in diabetic rats. The mechanism involved may be associated with the inhibition of renal tubular epithelial cell transdifferentiation, which can reduce tubulointerstitial fibrosis. However, the detailed mechanism involved remains to be clarified.

\section{Acknowledgements}

This study was supported by the Shandong Province Outstanding Young Scientist Research Award Fund Project, no. BS2013 YY042.

\section{References}

1. Srivastava SP, Koya D and Kanasaki K: MicroRNAs in kidney fibrosis and diabetic nephropathy: roles on EMT and EndMT. Biomed Res Int 2013: 125469, 2013.

2. Thiery JP and Sleeman JP: Complex networks orchestrate epithelial-mesenchymal transitions. Nat Rev Mol Cell Biol 7: 131-142, 2006.
3. Lei P, Jiang Z, Zhu H, Li X, Su N and Yu X: Poly(ADP-ribose) polymerase-1 in high glucose-induced epithelial-mesenchymal transition during peritoneal fibrosis. Int J Mol Med 29: 472-478, 2012.

4. Iwano M, Plieth D, Danoff TM, Xue C, Okada H and Neilson EG: Evidence that fibroblasts derive from epithelium during tissue fibrosis. J Clin Invest 110: 341-350, 2002.

5. The GISEN Group: Randomized placebo-controlled trial of effect of ramipril on decline in glomerular filtration rate and risk of terminal renal failure in proteinuric, non-diabetic nephropathy. Lancet 349: 1857-1863, 1997.

6. Maschio G, Alberti D, Janin G, Locatelli F, Mann JF, Motolese M, Ponticelli C, Ritz E and Zucchelli P: Effect of the angiotensinconverting-enzyme inhibitor benazepril on the progression of chronic renal insufficiency. The Angiotensin Converting Enzyme Inhibition in Progressive Renal Insufficiency Study Group. N Engl J Med 334: 939-945, 1996.

7. Peng T, Hu Z, Xia Q, Jiang B, Li X and Yang X: A comparative study of the renoprotective effects of benidipine and valsartan in primary hypertensive patients with proteinuria. Arzneimittelforschung 59: 647-650, 2009.

8. Kanno Y, Okada H, Yamaji Y, Nakazato Y and Suzuki H: Angiotensin-converting-enzyme inhibitors slow renal decline in IgA nephropathy, independent of tubulointerstitial fibrosis at presentation. QJM 98: 199-203, 2005.

9. Zhang Z, Wu F, Zheng F and Li H: Adenovirus-mediated decorin gene transfection has therapeutic effects in a streptozocin-induced diabetic rat model. Nephron Exp Nephrol 116: e11-e21, 2010.

10. Dada MO, Campbell GT, Horacek MJ and Blake CA: Intraperitoneal injection of chloral hydrate causes intraabdominal adhesions and unilateral testicular atrophy in golden Syrian hamsters. Life Sci 51: 29-35, 1992.

11. Magil AB: Tubulointerstitial lesions in human membranous glomerulonephritis: relationship to proteinuria. Am J Kidney Dis 25: $375-379,1995$.

12. Zhu Y, Yin WL, Ba YF, Tian L, Gu ZQ, Zhang MS and Zhong CN: Transforming growth factor-1 promotes the transcriptional activation of plasminogen activator inhibitor type 1 in carcinomaassociated fibroblasts. Mol Med Rep 6: 1001-1005, 2012.

13. Trieschmann M, Heimes B, Hense HW and Pauleikhoff D: Macular pigment optical density measurement in autofluorescence imaging: comparison of one- and two-wavelength methods. Graefes Arch Clin Exp Ophthalmol 244: 1565-1574, 2006.

14. Li L, Emmett N, Mann D and Zhao X: Fenofibrate attenuates tubulointerstitial fibrosis and inflammation through suppression of nuclear factor $-\kappa \mathrm{B}$ and transforming growth factor- $\beta 1 / \mathrm{Smad} 3$ indiabetic nephropathy. Exp Biol Med (Maywood) 235: 383-391, 2010.

15. Gilbert RE and Cooper ME: The tubulointerstitium in progressive diabetic kidney disease: more than an aftermath of glomerular injury? Kidney Int 56: 1627-1637, 1999.

16. Sagar SK, Zhang C, Guo Q, Yi R and Lin-Tang: Role of expression of endothelin-1 and angiotensin II and hypoxiainducible factor- $1 \alpha$ in the kidney tissues of patients with diabetic nephropathy. Saudi J Kidney Dis Transpl 24: 959-964, 2013.

17. Loeffler I, Liebisch M and Wolf G: Collagen VIII influences epithelial phenotypic changes in experimental diabetic nephropathy. Am J Physiol Renal Physiol 303: F733-F745, 2012.

18. Czernobilsky B, Gabbiani G, Prus D and Lifschitz-Mercer B: $\alpha$-smooth muscle actin-positive myofibroblasts in endometrial stroma are not a reliable criterion for the diagnosis of well differentiated endometrioid adenocarcinoma in small tissue samples. Int J Gynecol Pathol 20: 232-238, 2001.

19. Wei J, Shi Y, Hou Y, Ren Y, Du C, Zhang L, Li Y and Duan H: Knockdown of thioredoxin-interacting protein ameliorates high glucose-induced epithelial to mesenchymal transition in renal tubular epithelial cells. Cell Signal 25: 2788-2796, 2013.

20. Shi Y, Lo CS, Chenier I, Maachi H, Filep JG, Ingelfinger JR, Zhang SL and Chan JS: Overexpression of catalase prevents hypertension and tubulointerstitial fibrosis and normalization of renal angiotensin-converting enzyme-2 expression in Akita mice. Am J Physiol Renal Physiol 304: F1335-F1346, 2013.

21. Al-Malki AL, Sayed AA and El Rabey HA: Proanthocyanidin attenuation of oxidative stress and $\mathrm{NF}-\kappa \mathrm{B}$ protects apolipoprotein E-deficient mice against diabetic nephropathy. Evid Based Complement Alternat Med 2013: 769409, 2013.

22. Yang J, Dai C and Liu Y: Hepatocyte growth factor gene therapy and angiotensin II blockade synergistically attenuate renal interstitial fibrosis in mice. J Am Soc Nephrol 13: 2464-2477, 2002. 